in the greater part of the African continent; why did typhus not appear in the United States and Canada till its introduction by the Irish immigrants? why in America does it chiefly affect the eastern seaboard and spread mainly among the Irish who have landed there?-my answer is that each family of the human race and each climate has its own proper specific diseases. And if I am further asked, Why has typhus never gained a footing in Australia, Polynesia, and New Zealand? - I cannot refrain from replying that the lands whose indigenous quadrupeds are stunted, and whose evergreen forests are the marvel of the traveller, may, for aught we know, be inimical to the generation and spread of the poison; moreover, these countries are in the European sense new countries, and, if we only give them time, the habits of the Celtic Irish may yet succeed in developing typhus there as they have developed it at home.

Whatever may be thought of the views I have ventured to submit, I believe that there will be agreement on two points: first, that the doctrine of the independent origin of typhus will, wherever accepted, exert a more quickening effect on local authorities than its opponent; and secondly, that the history of these thirteen outbreaks, occurring for the chief part in the most densely popuIated districts of Dundee, and affecting only fifty-four persons in all, demonstrates, beyond the shadow of a doubt, the ability and success with which our public health work is conducted by Dr. Anderson, Mr. Kinnear, and the other officials of the sanitary department. But for their efforts, the labouring classes of Dundee might now be suffering from a typhus epidemic of overwhelming magnitude and mortality.

\section{ON A CASE OF ACUTE TONSILLITIS IN SUBJECT OF TERTIARY SYPHILIS OF THE PHARYNX.}

Bx H. W. G. MACKENZIE, M.A., M.B., M.R.C.S., RESIDENT ASSISTANT-PHYSICIAN TO ST. THOMAS'S HOSPITAL, FORMERLY CLINICAI ASSISTAN'T IN THE THROAT DEPARTMENT.

CASES in which the soft palate forms adhesions to the posterior wall of the pharynx are not very rarely seen among patients who have been the subjects of syphilitic ulceration in these parts. The appearance which such a case presents on examination of the fauces is not a little bewildering to the uninitiated. Once seen and understood, however, it will afterwards be easily recognised. There is no palatine arch, and probably no uvula. The roof of the mouth and pillars of the fauces, hardly to be recognised as such, are quite continuous with the posterior wall of the pharynx. The naso-pharynx is seldom quite shut off from the rest of the pharyngeal cavity. Behind the edge of the hard palate there may be a perforation of the soft palate, or it may be that one of the posterior pillars has not become completely adherent, thus leaving in either case a small round opening sufficient for the passage of air. The adhesion probably begins from below. If there is a perforation already formed in the soft palate, then, as Schech has pointed out, the adhesion will in all probability become complete. In this case the movements of the soft palate are much impaired, and to a certain extent unnecessary, on account of the permanent communication between the two cavities. Thus the soft palate is allowed to remain in contact with the pharyngeal wall. In the absence of perforation the continued passage of air will probably prevent complete adhesion taking place. The process must be a very gradual and mearly a painless one, otherwise it is difficult to explain why such patients have allowed it to go on without applying for treatment. Although such a case as this is unmistakable, it may, when complicated, lead to difficulty of diagnosis. If an attack of acute tonsillitis, an oedematous pharyngitis, a gummatous infiltration, or a malignant growth should occur, the appearance will then be very puzzling, and diagnosis probably impossible, until the case has been watched for some time. To Dr. Semon I am indebted for kindly allowing me to publish a case in point which lately presented itself at his clinique in the department for diseases of the throat, St. Thomas's Hospital.

E. O'D - a married woman, aged forty-four, applied at the throat department complaining of pain in her throat and difficulty of swallowing, which had come on a few days previously. She also suffered from general malaise. It was with difficulty that she could open her mouth sufficiently to allow even an imperfect view of the fauces. The appearance then revealed was somewhat extraordinary. The whole of the left and the greater part of the right side of the isthmus faucium were occupied by a swelling, which so displaced the surrounding parts that it was with difficulty they could be made out. The swelling was continuous on the left with what looked like the left anterior pillar, and above with the soft palate. The root of the tongue was pushed down on the left side by the swelling. On the right side a small opening remained for the passage of food and air, but the posterior wall of the pharynx could not be seen. At the upper part of the swelling, and pushed over to the right of the middle line, was a small œdematous body, identified by its situation as the uvula. It consisted of a round mass about the size of a pea, suspended ty a short thread-like pedicle from the upper part of the swelling. The swelling did not fluctuate, and was not very sensitive to touch. No enlargement of glands was to be detected in the neck. While from the symptoms one had expected to find on examination the appearances of an ordinary tonsillitis, what was seen was very different. The swelling, whatever it was, seemed to be one not confined to the tonsil, but involving also the soft palate and probably the posterior wall of the pharynx; the appearance, in fact, was that of a malignant growth or an infiltrating gummatous deposit.

The history of the patient was that she had suffered from sore-throat off and on for twenty-five years. She had been married nineteen years, and had had five children and two miscarriages. The children were said to be healthy. It appeared that she had applied at the throat department five months previously, but had only come once. On reference to the former notes of the case, it was found that the appearance at that time had been almost precisely the same. Dr. Semon then had left the diagnosis $2 n$ suspenso, and had put down "acute tonsillitis (?); malignant disease (?) syphilis (?)." As to what had been the condition in the interval we were left completely in the dark. We had only the patient's word for it that she had been comparatively well in the meantime. I may add that there were no signs of choroiditis on ophthalmoscopic examination. The diagnosis was left once more doubtful.

The patient was ordered to take ten grains of iodide of potassium, along with a saline aperient, thrice a day, and two grains of guaiacum, in the form of a lozenge, every two hours. She was strictly enjoined to return in a week. She did return, and happily the mystery was solved. The swelling had greatly subsided and a good view could be obtained. It was at once seen that the case was one of syphilitic pharyngeal stenosis, which had been complicated with an acute tonsillitis. The soft palate had formed adhesions to the posterior wall of the pharynx everywhere, except a little to the right of the middle line, where there was a small opening leading to the naso-pharynx and admitting the passage of a small probe. The swelling evidently was seated in the left tonsil, which, in consequence of the adhesions, was so abnormally situated as to appear to spring from the posterior wall of the pharynx, as well as to be continuous with the left anterior pillar of the fauces. The remains of the uvula presented the same appearance as on the previous attendance, except that the cedema had subsided. The character of the attack, its rapid course, and its tendency to recur left no doubt that it had been acute tonsillitis. The patient remained under observation a few weeks, and then ceased attending. It was elicited by crossexamination that twenty-five years ago she had had what was probably secondary syphilis, having been in hospital at Tralee with a general eruption over the body, and having then been treated with medicine which made the gums sore. The case was thus a very interesting one, and from its rarity and temporary obscurity is worth recording.

A GENEROUs and ungrudging manner of conducting insurance business deserves to be noticed. The Law Fire Insurance Society has, we learn, just awarded a gratuity of $£ 300$ in alleviation of a loss by fire sustained by a medical man who practises on the Continent, and who had omitted to keep up the payment of the premium on his insurance for $£ 500$, in respect of some stored furniture, which was destroyed by fire eight months after the last payment. 